Jurnal Penelitian Perawat Profesional

Volume 3 Nomor 1, Februari 2021

e-ISSN 2715-6885; p-ISSN 2714-9757

http://jurnal.globalhealthsciencegroup.com/index.php/JPPP

\title{
FAKTOR-FAKTOR YANG BERHUBUNGAN DENGAN PEMANFAATAN POS PEMBINAAN TERPADU PENYAKIT TIDAK MENULAR
}

\author{
Christin Angelina Febriani, Agung Aji Perdana, Tati Diana Sari* \\ Magister Kesehatan Masyarakat, Fakultas Kesehatan Masyarakat, Universitas Malahayati \\ Jl. Pramuka No. 27, Kemiling, Bandar Lampung, Indonesia 35152 \\ *tatidianasari@gmail.com (+62821 7896 9226)
}

\begin{abstract}
ABSTRAK
Hampir tiga perempat dari semua kematian penyakit tidak menular dan $82 \%$ dari 16 juta orang yang meninggal sebelum mencapai usia 70 tahun, terjadi pada penduduk berpenghasilan rendah dan menengah. Munculnya PTM disebabkan empat faktor risiko utama: penggunaan tembakau, aktivitas fisik, konsumsi alkohol dan diet yang tidak sehat. Tujuan penelitian diketahui faktorfaktor yang berhubungan dengan pemanfaatan Pos Pembinaan Terpadu Penyakit Tidak Menular. Jenis penelitian kuantitatif dengan menggunakan pendekatan cross sectional. Populasi sumber penelitian ini masyarakat di Wilayah Kerja Puskesmas Tegineneng Kabupaten Pesawaran sebanyak 27.208 Jiwa, sampel sebanyak 385 pengambilan sampel secara purposive sampling. Pengumpulan data menggunakan kuesioner yang sudah diuji validitas dan realibilitas pada penelitian sebelumnya, analisis data secara univariat untuk mendapatkan gambaran umum tentang tiap variabel, bivariat dengan uji chi square dan multivariat menggunakan analisis regresi linier logistik berganda. Hasil penelitian di dapatkan bahwa tidak ada hubungan ekonomi, tingkat pendidikan dengan pemanfaatan posbindu dan ada hubungan persepsi, sikap, peran petugas kesehatan, dukungan keluarga dan akses dengan pemanfaatan posbindu. Sikap merupakan faktor yang paling dominan dalam pemanfaatan posbindu jika dibandingkan faktor yang lainnya karena Exp (B) paling besar yaitu nilai OR 4,060.
\end{abstract}

Kata kunci: penyakit tidak menular; pos pembinaan terpadu

\section{FACTORS RELATED TO THE UTILIZATION OF INTEGRATED DEVELOPMENT POST DISEASE IS NOT CONTACTIVE}

\begin{abstract}
Nearly three-quarters of all non-communicable disease deaths and $82 \%$ of the 16 million people who die before reaching the age of 70 occur in the low and middle income population. The emergence of PTM is caused by four main risk factors: tobacco use, physical activity, alcohol consumption and an unhealthy diet. The aim of the study is to find out the factors associated with the use of the Integrated Non-Communicable Diseases Development Post. This type of quantitative research uses a cross sectional approach. The population of this research source is 27,208 people in the Tegineneng Public Health Center of Pesawaran District, 385 samples taken by purposive sampling. Data collection using questionnaires, univariate, bivariate and multivariate data analysis. The results showed that there was no economic relationship, educational level with the use of posbindu and there was a relationship between culture, attitudes, the role of health workers, family support and access to the use of posbindu. Attitude is the most dominant factor in the use of posbindu when compared to other factors because Exp $(B)$ is the largest, namely the OR value of 4.060. Every health worker must provide support to the community, especially hypertension sufferers, to take advantage of posbindu.
\end{abstract}

Keywords: integrated guidance post; non-communicable diseases 


\section{PENDAHULUAN}

Penyakit tidak menular (PTM) dikenal juga sebagai penyakit kronis, tidak ditularkan dari orang ke orang. Hampir tiga perempat dari semua kematian PTM dan $82 \%$ dari 16 juta orang yang meninggal sebelum mencapai usia 70 tahun, terjadi pada penduduk berpenghasilan rendah dan menengah (WHO, 2017).

Organisasi kesehatan dunia (WHO) telah merekomendasikan agar memusatkan penanggulangan PTM melalui tiga komponen utama, yaitu surveilans faktor risiko, promosi kesehatan, dan pencegahan melalui inovasi dan reformasi manajemen Posbindu. Pengendalian PTM di Indonesia terdapat dalam UU RI No.36 tahun 2009 tentang penyakit tidak menular yang berisi upaya yang dilakukan dalam pengendalian penyakit tidak menular, yaitu pencegahan, pengendalian, penanganan, dan akibat yang ditimbulkan dari suatu penyakit. Salah satu upaya mengendalikan faktor risiko penyakit tidak menular melalui sebuah wadah yang disebut dengan Posbindu PTM (Pos Pembinaan Terpadu Penyakit Tidak Menular). Posbindu PTM merupakan suatu bentuk pelayanan yang melibatkan peran serta masyarakat melalui upaya promotifpreventif untuk mendeteksi dan mengendalikan secara dini keberadaan faktor risiko PTM secara terpadu (Kemenkes, 2012).

PTM membunuh penduduk dengan usia yang lebih muda. Di negara-negara dengan tingkat Pengeluaran rendah dan menengah, dari seluruh kematian yang terjadi pada orang-orang berusia kurang dari 60 tahun, 29\% disebabkan oleh PTM, sedangkan di negara-negara maju, menyebabkan $13 \%$ kematian. (Kemenkes, 2012).
Jumlah Posbindu PTM di Provinsi Lampung sebanyak 413 Posbindu PTM yang tersebar di 15 Kabupaten/Kota, Posbindu PTM terbanyak ada di Kabupaten Tulang Bawang sebanyak 60 Posbindu PTM diikuti Kabupaten Lampung Barat sebanyak 52 Posbindu PTM dan Kabupaten Pesawaran sebanyak 50 Posbindu PTM (Profil Dinkes Lampung, 2016)

Berdasarkan data dari Puskesmas Tegineneng, proporsi penyakit tidak menular di Wilayah kerja Puskesmas Tegineneng adalah penyakit kardiovaskular sebanyak 3,41\%, asma dan penyakit paru obstruktif kronis sebanyak 0,55\%, diabetes melitus sebanyak 1,45\%, kanker leher rahim dan payudara sebanyak $0,05 \%$, dan gangguan akibat cedera dan kecelakaan lalu lintas sebanyak 0,01\% (Puskesmas Tegineneng, 2020).

Berdasarkan hasil pra survei yang dilakukan peneliti bulan Mei 2020 diperoleh data jumlah kunjungan ke Posbindu PTM dengan kunjungan terbanyak pada usia lebih dari 25 tahun dimana pada tahun 2019 sebanyak 1.102 orang ke-8 Posbindu PTM yang ada di wilayah Kerja Puskesmas Tegineneng dengan rincian di Posbindu PTM Agung I sebanyak $172(15,6 \%)$ orang, Posbindu PTM Agung II sebanyak 167 (15,2\%) orang, Posbindu PTM Agung III sebanyak 142 (12,9\%) orang, Posbindu PTM Ogan sebanyak $162(14,7 \%)$ orang, Posbindu PTM Wates sebanyak 138 (12,5\%) orang, Posbindu PTM Baru sebanyak 120 $(10,9 \%)$ orang , Posbindu PTM Kejadian sebanyak $99(9,0 \%)$ orang dan Posbindu PTM Gumananti sebanyak 102(9,3\%) orang (Data Sekunder PKM Tegineneng, 2020) Dari data terlihat bahwa tidak ada satupun Posbindu PTM di Puskesmas 
Tegineneng dengan kunjungan 20\% Sedangkan indikator dalam pemanfaatan Posbindu PTM baik di Kabupaten maupun di Provinsi adalah sebesar 20\% (PKM Tegineneng, 2019).

Banyak hal yang mempengaruhi kunjungan ke Posbindu, menurut Andersen (1974) dalam Priyoto (2014) terdapat tiga kategori utama yang dilihat oleh masyarakat dalam Posbindu, yaitu : faktor predisposisi, faktor pendukung dan faktor kebutuhan. Faktor-faktor ini mencakup pengetahuan, sikap, kepercayaan, keyakinan, nilai nilai, berkaitan erat dengan karakteristik individu mencakup umur, tingkat pendidikan dan pekerjaan, status ekonomi, fasilitas, kebutuhan kesehatan yang dirasakan oleh keluarga (Priyoto, 2014).

Penelitian Mothlag (2015) Setelah estimasi model pendapatan, pendidikan, status pekerjaan, asuransi dan ukuran rumah tangga berpengaruh pada pemanfaatan Posbindu .

Berdasarkan wawancara yang dilakukan secara singkat kepada masyarakat yang ada di wilayah Kerja Puskesmas Tegineneng bulan Mei 2020, dari 10 orang yang dilakukan wawancara sebanyak 7 (70\%) tidak pernah berkunjung ke Posbindu PTM dan 3 (30\%) pernah ke Posbindu PTM untuk melakukan pemeriksaan kesehatan, dari 10 orang tersebut sebanyak $6(60 \%)$ orang mengatakan tidak mengetahui kegiatan Posbindu PTM ataupun manfaat dengan berkunjung ke Posbindu PTM, dari 10 orang tersebut sebanyak $7(70 \%)$ orang mengatakan jika sakit langsung ke Puskesmas. Dari 10 orang tersebut semuanya bekerja dan usia antara 25-49 tahun. Berdasarkan latar belakang di atas, maka peneliti ingin mengetahui Faktor-Faktor yang Berhubungan Dengan Pemanfaatan Pos Pembinaan Terpadu Penyakit Tidak Menular.

\section{METODE}

Jenis penelitian ini adalah penelitian kuantitatif dengan pendekatan Cross Sectional. Penelitian ini telah dilakukan bulan Juni-Juli 2020 di Wilayah Kerja Puskesmas Tegineneng Kabupaten Pesawaran. Penelitian ini telah dinyatakan Laik Etik melalui Surat Keterangan Laik Etik (Ethical Clearence) No. 1091/EC/KEPUNMAL/VIII/2020. Dalam penelitian ini sampel diambil secara purposive sampling sebanyak 385 orang. Pengumpulan data menggunakan lembar kuesioner pemanfaatan posbindu, kuesioner faktor persepsi, kuesioner peran petugas dan kuesioner dukungan keluarga. Kuesioner sudah pernah dilakukan uji validitas dan realibilitas, sehingga tidak melakukan uji validitas dan realibilitas lagi.

\section{HASIL}

Pengambilan sampel dengan kriteria sebagai berikut :

1. Responden yang beridentitas sebagai masyarakat di Wilayah Kerja Puskesmas Tegineneng Kabupaten Pesawaran.

2. Berusia $\geq 15$ tahun.

3. Bersedia menjadi responden dengan informed consent. 
Tabel 1.

Distribusi frekuensi Pemanfaatan Posbindu

\begin{tabular}{lccc}
\hline \multicolumn{1}{c}{ variabel } & kategori & f & $\%$ \\
\hline Pemanfaatan Posbindu & Ya & 185 & 48,1 \\
Pengeluaran & Tidak & 200 & 51,9 \\
\multirow{3}{*}{ Pendidikan } & Tinggi & 219 & 56,9 \\
& Rendah & 166 & 43,1 \\
Persepsi & Tinggi & 169 & 43,9 \\
& Dasar & 216 & 56,1 \\
Sikap & Positif & 186 & 48,3 \\
& Negatif & 199 & 51,7 \\
Peran Petugas & Positif & 169 & 43,9 \\
& Negatif & 216 & 56,1 \\
Dukungan Keluarga & Positif & 195 & 50,6 \\
\multirow{2}{*}{ Akses } & Negatif & 190 & 49,4 \\
& Positif & 183 & 47,5 \\
& Negatif & 202 & 52,5 \\
& Mudah & 189 & 49,1 \\
& Sulit & 196 & 50,9 \\
\hline
\end{tabular}

Tabel 2.

Hubungan Pengeluaran dengan Pemanfaatan Posbindu

\begin{tabular}{|c|c|c|c|c|c|c|c|c|}
\hline \multirow{3}{*}{ Pengeluaran } & \multicolumn{4}{|c|}{ Pemanfaatan Posbindu } & \multirow{2}{*}{\multicolumn{2}{|c|}{ Jumlah }} & \multirow{3}{*}{$p$-value } & \\
\hline & \multicolumn{2}{|c|}{$\mathrm{Ya}$} & \multicolumn{2}{|c|}{ Tidak } & & & & OR \\
\hline & $\mathrm{f}$ & $\%$ & $\mathrm{f}$ & $\%$ & $\mathrm{f}$ & $\%$ & & $95 \% \mathrm{CI}$ \\
\hline Tinggi & 115 & 52,5 & 104 & 47,5 & 219 & 100 & \multirow{2}{*}{0,056} & 1,516 \\
\hline Rendah & 70 & 42,2 & 96 & 57,8 & 166 & 100 & & $(1,010-2,277$ \\
\hline
\end{tabular}

Tabel 1, terlihat bahwa distribusi frekuensi responden tidak memanfaatkan Posbindu yaitu sebanyak $200 \quad(51,9 \%)$ responden, Pengeluaran Tinggi sebanyak 219 $(56,9 \%)$ responden, responden dengan Pendidikan Dasar sebanyak 216 $(56,1 \%)$ responden, responden dengan Persepsi negatif sebanyak 199 (51,7\%) responden, responden dengan sikap negatif sebanyak $216 \quad(56,1 \%)$ responden, responden yang mengatakan peran petugas kesehatan positif yaitu sebanyak 195 (50,6\%), Responden dengan dukungan keluarga negatif sebanyak $202(52,5 \%)$ responden dan responden dengan akses sulit yaitu sebanyak $196(50,9 \%)$ responden.

Tabel 2, hasil uji statistik diperoleh $p$ value $=0,056$ yang berarti $\mathrm{p}>\alpha=0,05$ (Ha diterima dan Ho ditolak), maka dapat disimpulkan bahwa tidak ada hubungan yang signifikan antara status Pengeluaran dengan pemanfaatan Posbindu.

Tabel 3, hasil uji statistik diperoleh $p$ value $=0,791$ yang berarti $\mathrm{p}>\alpha=0,05$ (Ha ditolak dan Hoditerima), maka dapat disimpulkan bahwa tidak ada hubungan antara tingkat pendidikan tentang pemanfaatan Posbindu. 
Tabel 3.

Hubungan Pendidikan tentang Pemanfaatan Posbindu

\begin{tabular}{|c|c|c|c|c|c|c|c|c|}
\hline \multirow{3}{*}{ Pendidikan } & \multicolumn{4}{|c|}{ Pemanfaatan Posbindu } & \multirow{2}{*}{\multicolumn{2}{|c|}{ Jumlah }} & \multirow{3}{*}{$\begin{array}{c}p- \\
\text { value }\end{array}$} & \multirow{3}{*}{$\begin{array}{c}\text { OR } \\
95 \% \\
\text { CI }\end{array}$} \\
\hline & \multicolumn{2}{|c|}{$\mathrm{Ya}$} & \multicolumn{2}{|c|}{ Tidak } & & & & \\
\hline & $\mathrm{f}$ & $\%$ & $\mathrm{f}$ & $\%$ & $\mathrm{f}$ & $\%$ & & \\
\hline Tinggi & 83 & 49,1 & 86 & 50,9 & 169 & 100 & & 1,079 \\
\hline Dasar & 102 & 47,2 & 114 & 52,8 & 216 & 100 & 0,791 & $(, 721-$ \\
\hline Jumlah & 185 & 48,1 & 200 & 51,9 & 385 & 100 & & $1,614)$ \\
\hline
\end{tabular}

Tabel 4.

Hubungan Persepsi dengan Pemanfaatan Posbindu

\begin{tabular}{|c|c|c|c|c|c|c|c|c|}
\hline \multirow{3}{*}{ Persepsi } & \multicolumn{4}{|c|}{ Pemanfaatan Posbindu } & \multirow{2}{*}{\multicolumn{2}{|c|}{ Jumlah }} & \multirow{3}{*}{$\begin{array}{c}p- \\
\text { value }\end{array}$} & \multirow{3}{*}{$\begin{array}{c}\text { OR } \\
95 \% \mathrm{CI}\end{array}$} \\
\hline & \multicolumn{2}{|c|}{ Ya } & \multicolumn{2}{|c|}{ Tidak } & & & & \\
\hline & $\mathrm{f}$ & $\%$ & $\mathrm{f}$ & $\%$ & $\mathrm{f}$ & $\%$ & & \\
\hline Positif & 137 & 73,7 & 49 & 26,3 & 186 & 100 & & 8,795 \\
\hline Negatif & 48 & 24,1 & 151 & 75,9 & 199 & 100 & 0,001 & $(5,551-13,937)$ \\
\hline
\end{tabular}

Tabel 5.

Hubungan Sikap dengan Pemanfaatan Posbindu

\begin{tabular}{|c|c|c|c|c|c|c|c|c|}
\hline \multirow{3}{*}{ Sikap } & \multicolumn{4}{|c|}{ Pemanfaatan Posbindu } & \multirow{2}{*}{\multicolumn{2}{|c|}{ Jumlah }} & \multirow{3}{*}{$\begin{array}{c}p- \\
\text { value }\end{array}$} & \multirow{3}{*}{$\begin{array}{c}\text { OR } \\
95 \% \mathrm{CI}\end{array}$} \\
\hline & \multicolumn{2}{|c|}{$\mathrm{Ya}$} & \multicolumn{2}{|c|}{ Tidak } & & & & \\
\hline & $\mathrm{f}$ & $\%$ & $\mathrm{f}$ & $\%$ & $\mathrm{f}$ & $\%$ & & \\
\hline Positif & 130 & 76,9 & 39 & 23,1 & 169 & 100 & & 9,758 \\
\hline Negatif & 55 & 25,5 & 161 & 74,5 & 216 & 100 & 0,001 & $(6,093-15,626)$ \\
\hline
\end{tabular}

Tabel 6.

Hubungan Peran Petugas Kesehatan dengan Pemanfaatan Posbindu $(\mathrm{n}=185)$

\begin{tabular}{|c|c|c|c|c|c|c|c|c|}
\hline \multirow{3}{*}{$\begin{array}{l}\text { Peran } \\
\text { Petugas } \\
\text { Kesehatan }\end{array}$} & \multicolumn{4}{|c|}{ Pemanfaatan Posbindu } & \multirow{2}{*}{\multicolumn{2}{|c|}{ Jumlah }} & \multirow{3}{*}{$\begin{array}{c}p- \\
\text { value }\end{array}$} & \multirow{3}{*}{$\begin{array}{c}\text { OR } \\
95 \% \mathrm{CI}\end{array}$} \\
\hline & \multicolumn{2}{|c|}{$\mathrm{Ya}$} & \multicolumn{2}{|c|}{ Tidak } & & & & \\
\hline & $\mathrm{f}$ & $\%$ & $\mathrm{f}$ & $\%$ & $\mathrm{f}$ & $\%$ & & \\
\hline Positif & 106 & 54,4 & 89 & 45,6 & 195 & 100 & & 1,673 \\
\hline Negatif & 79 & 41,6 & 111 & 58,4 & 190 & 100 & 0,010 & $(1,118-2,505)$ \\
\hline
\end{tabular}

Tabel 4, hasil uji statistik diperoleh $p$ value $=0,001$ yang berarti $\mathrm{p}<\alpha=0,05$ (H0 ditolak dan Ha diterima), maka dapat disimpulkan bahwa ada hubungan antara Persepsi dengan pemanfaatan Posbindu . Dengan nilai OR 8,795 berarti responden Persepsi positif memiliki peluang 8,795 kali lebih besar untuk memanfaatkan Posbindu jika dibandingkan dengan responden Persepsi negatif.
Hasil uji statistik diperoleh $p$-value $=$ 0,001 yang berarti $\mathrm{p}<\alpha=0,05$ (Ho ditolak dan Ha diterima), maka dapat disimpulkan bahwa ada hubungan antara sikap dengan pemanfaatan Posbindu. Dengan nilai OR 9,758 berarti responden dengan sikap positif memiliki peluang sebesar 9,758 kali lebih besar untuk memanfaatkan Posbindu jika dibandingkan dengan responden yang sikap negatif. 
Tabel 7.

Hubungan Dukungan Keluarga dengan Pemanfaatan Posbindu

\begin{tabular}{|c|c|c|c|c|c|c|c|c|}
\hline \multirow{3}{*}{$\begin{array}{l}\text { Dukungan } \\
\text { Keluarga }\end{array}$} & \multicolumn{4}{|c|}{ Pemanfaatan Posbindu } & \multirow{2}{*}{\multicolumn{2}{|c|}{ Jumlah }} & \multirow{3}{*}{ p-value } & \multirow{3}{*}{$\begin{array}{c}\text { OR } \\
95 \% \mathrm{CI}\end{array}$} \\
\hline & \multicolumn{2}{|c|}{$\mathrm{Ya}$} & \multicolumn{2}{|c|}{ Tidak } & & & & \\
\hline & $\mathrm{f}$ & $\%$ & $f$ & $\%$ & $\mathrm{f}$ & $\%$ & & \\
\hline Positif & 125 & 68,3 & 58 & 31,7 & 183 & 100 & \multirow{2}{*}{0,001} & 5,101 \\
\hline Negatif & 60 & 29,7 & 142 & 70,3 & 202 & 100 & & $(3,306-7,869)$ \\
\hline
\end{tabular}

Tabel 8.

Hubungan Akses dengan Pemanfaatan Posbindu

\begin{tabular}{lcccccccc}
\hline & \multicolumn{4}{c}{ Pemanfaatan Posbindu } & \multicolumn{2}{c}{ Jumlah } & $p$ - & OR \\
\cline { 2 - 5 } Akses & \multicolumn{2}{c}{ Ya } & \multicolumn{2}{c}{ Tidak } & & value & $95 \%$ CI \\
\cline { 2 - 5 } & $\mathrm{f}$ & $\%$ & $\mathrm{f}$ & $\%$ & $\mathrm{f}$ & $\%$ & & 1,813 \\
Mudah & 105 & 55,6 & 84 & 44,4 & 189 & 100 & \multirow{2}{*}{0,005} & $(1,210-2,716)$ \\
Sulit & 80 & 40,8 & 116 & 59,2 & 196 & 100 & & \\
\hline
\end{tabular}

Tabel 6, hasil uji statistik diperoleh $p$ value $=0,016$ yang berarti $\mathrm{p}>\alpha=0,05$ (H0 ditolak dan Ha diterima), maka dapat disimpulkan bahwa ada hubungan antara peran petugas kesehatan dengan pemanfaatan Posbindu. Dengan nilai OR 1,673 berarti responden yang mengatakan peran petugas kesehatan positif memiliki peluang 1,673 kali lebih besar untuk memanfaatkan Posbindu jika dibandingkan dengan responden yang mengatakan peran petugas kesehatan negative.

Tabel 7, hasil uji statistik diperoleh $p$ value $=0,001$ yang berarti $\mathrm{p}<\alpha=0,05$ (Ho ditolak dan Ha diterima), maka dapat disimpulkan bahwa ada hubungan antara dukungan keluarga dengan pemanfaatan Posbindu . Dengan nilai OR 5,101 berarti responden dengan dukungan keluarga positif memiliki peluang 5,101 kali lebih besar untuk memanfaatkan Posbindu jika dibandingkan dengan responden yang dukungan keluarga negative.

Tabel 8, hasil uji statistik diperoleh $p$ value $=0,005$ yang berarti $\mathrm{p}<\alpha=0,05$ (H0 ditolak dan Ha diterima), maka dapat disimpulkan bahwa ada hubungan antara akses dengan pemanfaatan
Posbindu . Dengan nilai OR 1,813 berarti responden dengan akses mudah memiliki peluang 1,813 kali lebih besar untuk memanfaatkan Posbindu jika dibandingkan dengan responden dengan akses sulit.

\section{PEMBAHASAN}

Karakteristik sampel yang digunakan sebagai berikut :

1. Responden yang beridentitas sebagai masyarakat di Wilayah Kerja

Puskesmas Tegineneng Kabupaten

Pesawaran.

2. Berusia $\geq 15$ tahun.

3. Bersedia menjadi responden dengan informed consent.

\section{Hubungan Pengeluaran dengan Pemanfaatan Posbindu}

Sosial Pengeluaran merupakan faktor predisposisi dalam pemanfaatan fasilitas kesehatan, selain sosial Pengeluaran faktor predisposisi lainnya yang berkaitan dengan pemanfaatan fasilitas kesehatan adalah budaya, jenis kelamin dan geografis. Menurut Kriger et al., dalam Owoseni Joseph Sina et al., status sosial Pengeluaran merupakan konsep multidimensi (Rabbaniyah, 2019). Dimensi yang terkait dengan status sosial Pengeluaran adalah status 
pekerjaan, prestasi, pendidikan, pendapatan, kemiskinan dan kekayaan. Menurut Abodurin et al., dalam Owo seni Joseph Sina et al., pemilihan fasilitas kesehatan ditentukan oleh selera individu, kepuasan pelayanan, dan kualitas perawatan yang diberikan. Pendapatan berkaitan erat dengan pekerjaan. Seseorang yang memiliki pekerjaan akan menghasilkan sebuah pendapatan untuk memenuhi kebutuhan sehari-hari. Salah satu faktor sosioPengeluaran konsumen yang mempengaruhi dalam pelayanan kesehatan adalah pekerjaan. Seseorang yang memiliki pekerjaan akan cenderung untuk memanfaatkan fasilitas kesehatan untuk berobat jalan, karena seseorang tersebut memiliki kemampuan dalam membiayai pelayanan kesehatan (Syarifain, 2019).

Berdasarkan hasil penelitian diketahui bahwa dari 166 responden dengan Pengeluaran rendah, sebanyak 70 $(42,2 \%)$ responden memanfaatkan Posbindu hal tersebut terjadi karena masyarakat menyadari bahwa kesehatan merupakan hal yang sangat penting dan harus dijaga.Kesadaran masyarakat ini yang mendorong mereka untuk memanfaatkan subsidi yang diberikan oleh pemerintah secara gratis dalam bentuk program jaminan kesehatan nasional (JKN) yang diterbitkan pada 1 Januari 2014.

Dilihat dari rata-rata penghasilan responden per bulan didapatkan bahwa responden yang berpenghasilan tinggi lebih banyak memanfaatkan pelayanan kesehatan dibandingkan dengan yang berpenghasilan rendah hal ini dikarenakan responden yang berpenghasilan tinggi mereka masih bisa menggunakan sebagian kecil penghasilannya untuk memeriksakan kesehatan di fasilitas kesehatan yang telah disediakan berbeda dengan yang memiliki penghasilan rendah mereka beranggapan jika penghasilan mereka disimpan untuk hal yang dianggap jauh lebih penting. Tidak ada hubungan antara penghasilan dengan pemanfaatan pelayanan kesehatan.

\section{Hubungan pendidikan tentang Pemanfaatan Posbindu}

Status pendidikan sangat erat kaitannya dengan kesadaran dan pengetahuan seseorang, sehingga status pendidikan memiliki pengaruh yang signifikan terhadap pemanfaatan pelayanan kesehatan. Biasanya masyarakat yang berpendidikan rendah, kurang memiliki kesadaran dan pengetahuan yang baik tentang manfaat pelayanan pelayanan kesehatan (Rumengan, Umboh, \& Kandou, 2015). Tingkat pendidikan memiliki relevansi terhadap pengetahuan seseorang, sehingga hal tersebut berkontribusi pada persepsi masyarakat terhadap pentingnya kesehatan. Masyarakat yang berpendidikan tinggi cenderung menganggap kesehatan sebagai suatu hal yang penting, sehingga kecenderungan untuk memanfaatkan pelayanan kesehatan lebih besar dibandingkan masyarakat yang berpendidikan rendah.

Menurut pendapat peneliti dengan hasil analisis data menunjukkan bahwa tidak ada hubungan yang signifikan antara pendidikan dengan pemanfaatan Posbindu. Berdasarkan hasil penelitian diketahui bahwa dari 216 responden yang pendidikan dasar, sebanyak 114 $(52,8 \%)$ responden tidak memanfaatkan Posbindu, hal ini dikarenakan pendidikan masyarakat yang rendah cenderung menyebabkan pengetahuan yang rendah pula tentang pentingnya kesehatan. Mereka kurang memahami tentang manfaat pelayanan kesehatan 
dan kondisi yang ada pada dirinya yang mengharuskan agar dia segera mengakses pelayanan kesehatan. dan sebanyak $102(47,2 \%)$ responden memanfaatkan Posbindu, hal ini dikarenakan masyarakat dengan tingkat pendidikan rendah tetapi menyadari akan pentingnnya kesehatan akan berpengaruh terhadap pemanfaatan pelayanan Puskesmas. Masyarakat yang memiliki kesadaran akan kesehatannya akan memahami tentang manfaat pelayanan, tanda-tanda bahaya atau kegawatan yang memerlukan pelayanan Puskesmas.

\section{Hubungan Persepsi dengan Pemanfaatan Posbindu}

Kondisi ini membutuhkan cara-cara intervensi yang lokal spesifik dan tidak dapat digeneralisasi secara nasional. Persepsi berhubungan dengan kebiasaan atau kepercayaan kesehatan adalah sebuah bentuk perilaku dimana seseorang memberikan penilaian dan penjabaran terhadap kesehatan dari segi sosio-psikologis. Sedangkan perilaku merupakan kumpulan berbagai faktor yang saling berinteraksi. Sering tidak disadari bahwa interaksi tersebut amat kompleks sehingga kadangkadang seseorang tidak sempat memikirkan penyebab menerapkan perilaku tertentu. Pelayanan kesehatan yang baik adalah bersifat wajar (appropriate) dan dapat diterima oleh masyarakat. Artinya pelayanan kesehatan tersebut dapat mengatasi maalah kesehatan yang dihadapi, tidak bertentanan dengan adat istiadat, persepsi, keyakinan dan kepercayaan masyarakat serta bersifat yang wajar dilakukan demi penyembuhan. Konsep sakit dan penyakit dibentuk atas dasar nilai budaya setempat serta menimbulkan perilaku pemanfaatan fasilitas kesehatan yang dipengaruhi oleh struktur sosial setempat (Hermawan,
Pemanfaatan pelayanan kesehatan hasil dari proses pencarian pelayanan kesehatan oleh seseorang maupun kelompok.

Menurut peneliti struktur sosial erat kaitannya dengan Persepsi salah satunya meliputi Persepsi dalam pemilihan pengobatan. Sumber pengobatan di dunia mencakup tiga sektor yang saling terkait yaitu pengobatan rumah tangga atau pengobatan sendiri, pengobatan tradisional dan pengobatan medis yang dilakukan oleh perawat, dokter, Puskesmas atau Rumah Sakit. hasil penelitian ini menunjukan masyarakat sebagain masyarakat sudah mulai mengurangi kegiatan pengobatan tradisional yang magis dan lebih banyak responden yang memilih untuk berobat ke layanan kesehatan. Alasan lain masyarakat tidak menggunakan pengobatan tradisional yaitu dari segi tenaga dan biaya yang lebih besar dibandingkan ke pelayanan kesehatan.

\section{Hubungan sikap dengan Pemanfaatan Posbindu}

Tingkat pengetahuan tentang posbindu pada kader kesehatan yang tinggi dapat membentuk sikap positif terhadap program posbindu khususnya ketidakaktifan untuk kunjungan ke posbindu, Pada gilirannya akan mendorong seseorang untuk aktif dan ikut serta dalam pelaksanaan posbindu. Tanpa adanya pengetahuan maka para sulit dalam menanamkan kebiasaan kunjungan ke Posbindu. Pengetahuan tentang posbindu akan berdampak pada sikap terhadap manfaat yang ada dan akan terlihat dari praktek dalam ketidak aktifan terhadap masalah kesehatannya. Tingkat pengetahuan seseorang dapat memengaruhi perilaku individu, dimana semakin tinggi tingkat pengetahuan tentang manfaat posbindu, maka semakin tinggi pula kesadaran untuk 
berperan serta dalam program posbindu. Pengetahuan tentang posbindu yang rendah akan menyebabkan rendahnya tingkat kesadaran untuk berkunjung ke Posbindu

\section{Hubungan Peran Petugas Kesehatan dengan Pemanfaatan Posbindu}

Petugas kesehatan adalah seseorang yang bertanggung jawab dalam memberikan pelayanan kesehatan kepada individu, keluarga dan masyarakat. Petugas kesehatan berdasarkan pekerjaannya adalah tenaga medis, dan tenaga paramedis seperti tenaga keperawatan, tenaga kebidanan, tenaga penunjang medis dan lain sebagainya. Ada dua aspek mutu pelayanan kesehatan yang perlu dilakukan di puskesmas yaitu quality of care dan quality of service. Quality of care antara lain menyangkut keterampilan tehnis petugas kesehatan (dokter, bidan, perawat atau paramedis lain) dalam menegakkan diagnosis dan memberikan perawatan kepada pasien (Kemenkes, 2014). Sikap petugas akan membentuk persepsi tentang pelayanan. Petugas yang memberikan kesan yang baik terhadap serta menunjukkan kemampuan, ketelitian, keterampilan dalam mengatasi kesulitan yang dialami dengan cepat sesuai dengan tuntunan akan membuat merasa percaya diri untuk memeriksakan kesehatan dan puas dengan pelayanan yang diberikan. Hal ini akan berdampak pada keinginan untuk datang ke pelayanan kesehatan tersebut.

Menurut pendapat peneliti kemampuan petugas kesehatan baik ditinjau dari pendidikan, pengetahuan dan sikap harus dapat diaktualisasikan secara baik seperti dalam pemberian motivasi terhadap penderita hipertensi agar mau untuk datang ke posbindusecara rutin, petugas kesehatan harus mampu memberikan manfaat dari posbindu sehingga dapat mempengaruhi masyarakat khusunya penderita hipertensi untuk mengikuti kegiatan posbindu. Peran puskesmas atau petugas kesehatan dalam kegiatan posbindu adalah sebagai fasilitator dan lebih memberdayakan masyarakat dalam kegiatan posbindu.Kegiatan posbindu dikatakan meningkat jika peran serta masyarakat semakin tinggi yang terwujud dalam cakupan program kesehatan. Berdasarkan hal diatas, direkomendasikan bahwa setiap petugas kesehatan harus memberikan dukungan kepada masyarakat khususnya penderita hipertensi untuk memanfaatkan Posbindu. Oleh karena itu disarankan agar memotivasi petugas kesehatan memberikan informasi kepada setiap yang berkunjung ke Puskesmas atau fasilitas kesehatan lainnya dan keluarganya tentang manfaat Posbindu .

\section{Hubungan Dukungan Keluarga dengan Pemanfaatan Posbindu}

Dukungan adalah menyediakan sesuatu untuk memenuhi kebutuhan orang lain. Dukungan juga dapat diartikan sebagai memberikan dorongan / motivasi atau semangat dan nasihat kepada orang lain dalam situasi pembuat keputusan. dukungan adalah informasi verbal atau non verbal, saran, bantuan, yang nyata atau tingkah laku diberikan oleh orangorang yang akrab dengan subjek didalam lingkungan sosialnya atau yang berupa kehadiran dan hal-hal yang dapat memberikan keuntungan emosional atau berpengaruh pada tingkah laku penerimanya atau dukungan adalah keberadaan, kesediaan, kepedulian dari orang-orang yang diandalkan, menghargai dan menyayangi kita (Friedman dalam Padila (2013) Pengukuran dukungan pada penelitian ini dilakukan dengan 
cara perceived social support. Dalam hal ini faktor subjektivitas sangat berpengaruh karena melibatkan persepsi penerimanya. Adanya penilaian kognitif bahwa individu telah menerima dukungan.

Hasil uji chi-square diperoleh nilai $\mathrm{p}$ sebesar 0.840, sehingga terbukti secara statistik tidak ada hubungan yang bermakna antara dukungan keluarga dengan pemanfaatan posbindu oleh lansia. Kesimpulan untuk dapat memanfaatkan layanan posbindu, maka bukan hanya dukungan keluarga yang diperlukan tetapi dukungan lain seperti perawat komunitas, peran serta kader kesehatan, dan unsur lain yang terkait.

Keluarga sebagai motivator kuat bagi penduduk untuk mengikuti kegiatan posbindu PTM apabila selalu menyediakan diri untuk mendampingi, mengantar atau mengingatkan jadwal posbindu PTM. Keberadaan anggota keluarga memainkan peranan penting dalam mencegah atau paling tidak menunda orang menderita sakit kronis ke lembaga Posbindu. Keluarga sebagai motivator kuat bagi penduduk untuk mengikuti kegiatan posbindu apabila selalu menyediakan diri untuk mendampingi, mengantar atau mengingatkan jadwal posbindu. Keberadaan anggota keluarga memainkan peranan penting dalam mencegah atau paling tidak menunda orang menderita sakit kronis ke lembaga Posbindu. Oleh sebab itu, petugas kesehatan perlu mengadakan konseling atau pendidikan kesehatan terhadap keluarga sehingga diharapkan melalui hal tersebut meningkatkan pula pengetahuan dan kesadaran keluarga tentang pentingnya peran serta di Posbindu.

\section{Hubungan Akses Pemanfaatan Posbindu \\ dengan}

Pengertian ketercapaian yang di maksud disini terutama dari sudut lokasi. Dengan demikian untuk dapat mewujudkan pelayanan kesehatan yang baik, maka pengaturan distribusi sarana kesehatan menjadi sangat penting. Pelayanan kesehatan yang terlalu terkonsentrasi di daerah perkotaan saja, dan sementara itu tidak ditemukan di daerah pedesaan, bukan pelayanan kesehatan yang baik (Azwar,2015).

Hasil penelitian ini menunjukkan bahwa yang memanfaatkan posbindu mengatakan bahwa mereka dapat dengan mudah mengakses pelayanan, jarak antara rumah dengan posbindu dapat diakses dengan berjalan kaki. Apabila jarak antara rumah dengan posbindu cukup jauh menggunakan sarana transportasi mudah didapatkan dengan biaya terjangkau dan tidak menghabiskan waktu perjalanan lama.Selain itu, posbindu juga diantar oleh keluarga untuk memeriksakan kesehatannya yang kurang memanfaatkan posbindu mengatakan bahwa rumah mereka jauh dari posbindu selain itu, untuk memeriksakan kesehatan mereka menggunakan jasa bidan praktek yang lebih dekat dari rumah mereka, atau temapt fasilitas lain seperti Puskesmas. Menurut peneliti faktor geografis, jarak dan infrastruktur jalan sangat berpengaruh terhadap akses masyarakat untuk memanfaatkan posbindu khususnya pada masyarakat yang tinggal pada daerah terpencil.

\section{SIMPULAN}

Distribusi frekuensi responden tidak memanfaatkan Posbindu yaitu sebanyak $200 \quad(51,9 \%)$ responden, Pengeluaran Tinggi sebanyak 219 $(56,9 \%)$ responden, responden dengan 
Pendidikan Dasar sebanyak 216 $(56,1 \%)$ responden, responden dengan Persepsi negatif sebanyak $199(51,7 \%)$ responden, responden dengan sikap negatif sebanyak $216 \quad(56,1 \%)$ responden, responden yang mengatakan peran petugas kesehatan positif yaitu sebanyak 195 (50,6\%), Responden dengan dukungan keluarga negatif sebanyak $202(52,5 \%)$ responden dan responden dengan akses sulit yaitu sebanyak $196(50,9 \%)$ responden.

Tidak ada hubungan Pengeluaran dengan pemanfaatan Posbindu dengan $p$-value $=0,056$. Tidak ada hubungan tingkat pendidikan tentang pemanfaatan Posbindu $p$-value $=0,791$. Ada hubungan Persepsi dengan pemanfaatan Posbindu dengan $p$-value $=0,000$ dan OR 8,795. Ada hubungan sikap dengan pemanfaatan Posbindu $p$-value $=0,000$ dan OR 9,758. Ada hubungan peran petugas kesehatan dengan pemanafaatan Posbindu dengan $p$-value $=0,016$ dan OR 1,673. Ada hubungan dukungan keluarga dengan pemanfaatan Posbindu dengan $p$-value $=0,000$ dan OR 5,101. Ada hubungan akses dengan pemanfaatan Posbindu dengan $p$-value $=0.005$ dan OR 1,813. Sikap merupakan faktor yang paling dominan dalam Pemanfaatan Posbindu jika dibandingkan faktor yang lainnya karena $\operatorname{Exp}(\mathrm{B})$ paling besar yaitu nilai OR $4,060 \quad(95 \% \quad$ CI: $2,080-7,477)$ setelah di kontrol dengan variabel persepsi, dukungan keluarga serta petugas kesehatan.

\section{DAFTAR PUSTAKA}

Arikunto, Suharsimi. 2013. Prosedur penelitian suatu pendekatan praktik. PT Rineka Cipta : Jakarta.

Bakoil, M. B., Supriyanto, S., \& Koesbardiati, T. (2017). Hubungan Jaminan Persalinan,
Jarak Tempat Tinggal, Waktu Tempuh dan Kebiasaan Masyarakat Terhadap Pemanfaatan Tempat Persalinan Di Kabupaten Timor Tengah Selatan. Jurnal Info Kesehatan, 15(1), 82-96.

Budiman, A. R. 2013. Kapita Selekta Kuesioner : Pengetahuan dan Sikap dalam penelitian Kesehatan. Salemba Medika: Jakarta

Cahyati. (2015). Pengaruh dukungan keluarga dan tokoh masyarakat terhadap keaktifan penduduk ke posbindu tidak menular di Kota Semarang tahun 2015.

Darmawan, N. (2016). Faktor-Faktor Yang Mempengaruhi Perilaku Kunjungan Masyarakat Terhadap Pemanfaatan Pelayanan Posyandu Di Desa Pemecutan Kelod Kecamatan Denpasar Barat. Jurnal Dunia Kesehatan, 5(2), 76442.

Dinkes Lampung. (2016). Profil Kesehatan Lampung Tahun 2016, Lampung.

Gaol, Tiomarni Lumban. (2013). pengaruh faktor sosiodemografi, sosioPengeluaran dan kebutuhan terhadap perilaku masyarakat dalam pencarian pengobatan di Kecamatan Medan Kota. balitbang.pemkomedan.go.id/.pdf. program studi S2 Ilmu Kesehatan Masyarakat Fakultas Kesehatan Masyarakat Universitas Sumatera Utara.

Handayani, D. E. (2012). Pemanfaatan Pos Pembinaan Terpadu Oleh Lanjut Usia di kecamatan Ciomas kabupaten Bogor Tahun 2012 dan 
faktor yang berhubungan. Jurnal FKM UI.

Hermawan, C., Anggraeni, R., \& Setianingsih, S. (2017). Gambaran Upaya Dalam Mencari Bantuan Kesehatan Pada Masyarakat. Jurnal Keperawatan, 9(2), 52-59.

Jueriyah, J., Asmadi, A., \& Mashuri, M. Dukungan Keluarga dalam Pemanfaatan Posbindu oleh Lansia di Wilayah Puskesmas Haurgeulis Kabupaten Indramayu. Jurnal Ilmu Kesehatan Bhakti Husada, 2(2), 84-89.

Kemenkes RI. (2012). Data dan informasi penyakit tidak menular. http://www.depkes.go.id/folder/vi ew/01/structure-publikasipusdatin-buletin.html

Kemenkes RI. (2012). Petunjuk Teknis Pos Pembinaan Terpadu Penyakit Tidak Menular (Posbindu PTM).

Khodijah, Nyayu. 2014. Psikologi Pendidikan. Jakarta: Rajawali Pers.

Kim, Han-Kyoul., Munjae Lee. (2015). Factors associated with health services utilization between the years 2010 and 2012 in Korea: using Andersen's Behavioral model

http://www.sciencedirect.com/scie nce/article/pii

Levesque, J. F., Harris, M. F., \& Russell, G. (2013). Patientcentred access to health care: conceptualising access at the interface of health systems and populations. International journal for equity in health, 12(1), 18.

Logen, Y., \& Balqis, D. (2015). Faktor Yang Berhubungan Dengan
Pemanfaatan Pelayanan

Kesehatan Oleh Pemulung Di TPA Tamangapa. Skripsi. Universitas Hasanudin.

Misbah, N., \& Tansah, A. (2015). Faktor-Faktor Yang Mempengaruhi Pemanfaatan Pos Pembinaan Terpadu Oleh Lansia. Jurnal Medikes (Media Informasi Kesehatan), 2(2), 133-149.

Mothlag Nooraiee, Saber Mahani A, Barooni M, Asadi Lari M, Vaez Mahdavi M R, Hadian M. Determining Factors related to health services utilization: . RJMS. 2015; 21 (127) :61-72 (2015), Determining Factors related to health services utilization: Assistant Professor, Department of Health Economics, Iran University of Medical Sciences, Tehran, Iran Iran University of Medical Sciences, Tehran, Iran http://journal.iums.ac.ir/journalsys /rjms/browse.php?a_code $=\mathrm{A}-10-$ $1-1624 \&$ sid $=1 \&$ slc lang=en URL: http://rjms.iums.ac.ir/article-13475-en.html

Napirah, M. R., Rahman, A., \& Tony, A. (2016). Faktor-faktor yang berhubungan dengan pemanfaatan pelayanan kesehatan di wilayah kerja Puskesmas Tambarana Kecamatan Poso Pesisir Utara Kabupaten Poso. Jurnal Pengembangan Kota, 4(1), 29-39.

Notoatmodjo. (2012). Metode Penelitian. Jakarta: Rineka Cipta.

Notoatmodjo. (2012). Promosi Kesehatan dan Perilaku Kesehatan. Jakarta: Rineka Cipta. 
Padila. (2013). Buku Ajar Keperawatan Keluarga. Jogjakarta : Nuha Medika.

Perdana, A. A., Nuryani, D. D., \& Lestari, T.. (2017). Faktor-Faktor Yang Berhubungan Dengan Pemanfaatan Pos Pembinaan Terpadu Penyakit Tidak Menular Di Wilayah Kerja Puskesmas Rawat Inap Kemiling Bandar Lampung. Jurnal Dunia Kesmas Volume 6. Nomor 3 Juli 2017.

Perry, Potter. (2011). Buku Ajar Fundamental Keperawatan: Konsep,. Proses, Dan Praktik, edisi 4, Volume.2. Jakarta: EGC.

Priyoto. (2014). Teori Sikap dan Perilaku dalam Kesehatan. Yogyakarta: Nuha. Medika.

Purdiyani, F. (2016). Pemanfaatan Pos Pembinaan Terpadu Penyakit Tidak Menular (Posbindu Ptm) Oleh Wanita Lansia Dalam Rangka Mencegah Penyakit Tidak Menular Di Wilayah Kerja Puskesmas Cilongok 1. Jurnal Kesehatan Masyarakat (eJournal), 4(1), 470-480.

Rabbaniyah. (2019), Analisis Sosial Pengeluaran dalam Pemanfaatan Fasilitas Kesehatan untuk Berobat Jalan di Provinsi Jawa Barat : Analisis Data Susenas Tahun 2017.

Riskesdas. 2018. Riset Kesehatan Dasar dalam angka Provinsi Lampung. Kemenkes 2018.

Riyanto, A. 2011. Aplikasi Metodologi Penelitian Kesehatan. Nuha medika: Yogyakarta.

Roudsari, R. L., Zakerihamidi, M., \& Khoei, E. M. (2015). Socio- cultural beliefs, values and traditions regarding women's preferred mode of birth in the North of Iran. International journal of community based nursing and midwifery, 3(3), 165.

Saam. (2014). Psikologi Keperawatan. Rajawali Pres: Jakarta.

Sandra, P. N., \& Kusumaningrum, I. D. (2019). Pengetahuan, Sikap Dan Dukungan Keluarga Tentang Pemanfaatan Posbindu Penyakit Tidak Menular Di Kretek Bantul. Surya Medika: Jurnal Ilmiah Ilmu Keperawatan dan Ilmu Kesehatan Masyarakat, 13(2).

Saptaputra. (2016). Faktor yang Berhubungan dengan Pemanfaatan Posbindu di UPTD Puskesmas Langara Kecamatan Wawonini Barat Kabupaten Konawe Kepulauan Tahun 2016. Jurnal penelitian.

Septriliyana, R. N., \& WE, S. (2011). Hubungan Pengetahuan dengan Sikap Lansia Mengenai Posbindu di RW 07 Desa Kertawangi Kecamatan Cisarua Kabupaten Bandung Barat Tahun 2011 [Internet]. 2011 [cited 2015 April 17]. Jurnal Kesehatan Kartika, 2(1), 43-9.

Simbolon, D., Astuti, W. D., \& Andriani, L. (2015). Mekanisme Hubungan Sosial Ekonomi, Pemanfaatan Pelayanan Kesehatan dan Kehamilan Risiko Tinggi terhadap Prevalensi Panjang Badan Lahir Pendek. Kesmas: National Public Health Journal, 9(3), 235-242.

Siswanto. (2014). Metodologi penelitian kesehatan dan kedokteran. Bursa ilmu: Jakarta. 
Sugiyono. (2017). Metode Penelitian Kuantitatif Kualitatif dan $R \& D$. Alfabeta: Bandung.

Supriyatna, E., Pertiwiwati, E., \& Setiawan, H. (2020). PROGRAM POS PEMBINAAN TERPADU PENYAKIT TIDAK MENULAR DI PUSKESMAS

MARTAPURA. Jurnal Publikasi Kesehatan Masyarakat Indonesia, 7(1), 1-8.

Syarifain, A., Rumayar, A. A., \& Mandagi, C. K. (2017). Hubungan antara Pendidikan dan Pendapatan dengan Pemanfaatan Pelayanan Kesehatan oleh Pasien BPJS di Wilayah Kerja Puskesmas Sario Kota Manado. KESMAS, 6(4).

Tampi, J., Rumayar, A. A., \& Tucunan, A. A. (2016). Hubungan antara pendidikan, pendapatan dan pekerjaan dengan pemanfaatan pelayanan kesehatan di rumah sakit umum daerah ManemboNembo Bitung 2015. Kesmas, 5(1).

Tanjung, W. W., Harahap, Y. W., \& Panggabean, M. S. (2018). Faktor-Faktor Yang Mempengaruhi Pemanfaatan Program Pos Pembinaan TerpaduPenyakit Tidak Menular Di Wilayah Kerja Puskesmas Batang Toru KabupatenTapanuli Selatan Tahun 2017. Jurnal Kesehatan Ilmiah Indonesia (Indonesian Health Scientific Journal), 3(2), 92-108.

Tjiptono, F. (2015). Strategi Pemasaran, edisi keempat. CV Andi Offset: Yogyakarta.

Widiani, I., Junaid, J., \& Lisnawaty, L. (2015). Faktor Yang Berhubungan Dengan Pemanfaatan Pelayanan
Kesehatan Ibu Dan Anak Di Puskesmas Tomia Timur Kelurahan Tongano Timur Kabupaten Wakatobi Tahun 2015. (Jurnal Ilmiah Mahasiswa Kesehatan Masyarakat), 1(3).

World Health Organization Geneva, Switzerland. (2017) What are noncommunicable diseases and their risk factors?http://www.who.int/ncds/e $\underline{\mathrm{n} /}$ 